\title{
An Investigation of the Correlation between Pollutant Dispersion and Wind Environment: Evaluation of Static Wind Speed
}

\author{
Li Yan, Wen Hu*, Ming-Qiang Yin \\ School of Architecture and Urban Planning, Chongqing University, Chongqing 400045, China
}

Received: 24 March 2020

Accepted: 3 November 2020

\begin{abstract}
The research on the correlation between pollutant dispersion and wind environment is gaining more and more attention due to increasingly serious air pollution. However, the specific relationship between wind environment factors and the pollutant concentration is still unclear. In this paper, a simple model of the relationship among wind speed, pollutant concentration, and pollutant dispersion efficiency is investigated based on computational fluid dynamics (CFD) simulations to redefine the static wind speed on the aspect of pollutant dispersion. The air pollutants are supposed to be diffused effectively when the wind speed is higher than the static wind speed. The CFD simulations are performed using the three-dimensional steady and unsteady Reynolds-averaged Navier-Stokes (RANS) methods. First, the numerical methods and CFD settings are described briefly and then validated by experimental data. Next, an idealized pollutant dispersion model is established and then the pollutant dispersion processes are simulated and analyzed with different wind speed profiles. Finally, wind with speed less than $1.0 \mathrm{~m} / \mathrm{s}$ at pedestrian level (1.5 m above the ground) is defined as static wind according to the comparison and analysis. It is expected that the static wind speed results can be easily used as an indicator to evaluate air quality directly for urban design and planning.
\end{abstract}

Keywords: wind environment, static wind speed, pollutant dispersion, computational fluid dynamics (CFD)

\section{Introduction}

Currently, $55 \%$ of the global population lives in cities. It is expected that the global urbanization rate will increase up to $68 \%$ by 2050 [1]. Rapid urbanization leads to population agglomeration and economic growth, however, it also brings about continuous deterioration

*e-mail: huwen678@163.com of air quality in urban environments. According to statistics from the World Health Organization (WHO), air quality in most cities of the world is under the stipulated limits. Only $12 \%$ of urban residents live in areas where the air quality meets the WHO standards, while the air pollution levels in approximately half of the cities are at least 2.5 times higher than the WHO standard [2]. It is estimated that more than one billion people are exposed to poor-quality air, which causes one million premature deaths each year. Therefore, without appropriate mitigation measures, air pollution 
Table 1. Overview of studies on the relationship between wind environment and urban pollution dispersion.

\begin{tabular}{|c|c|c|c|c|c|c|c|}
\hline Study & Ref. & Scale & Geometry & Model & Grid & Validation & Focus \\
\hline Du et al. (2020) & {$[6]$} & Building & Genetic & LES (Dyn.) & Str. & WT & a \\
\hline Rivas et al. (2019) & [7] & City & Real & RANS (RKE) & Un-Str. & Field & $a, b$ \\
\hline Yuan et al. (2019) & {$[13]$} & City & Genetic & RANS (SSTKO) & Str. & WT & $\mathrm{b}$ \\
\hline Li et al. (2019) & {$[14]$} & Neighb. & Real & RANS (RKE) & Un-Str. & WT\& Field & $\mathbf{b}$ \\
\hline Kikumoto et al. (2018) & {$[8]$} & Street & Genetic & LES (Dyn.) & Cart. & Field & $\mathrm{a}, \mathrm{b}$ \\
\hline Lau et al. (2018) & {$[20]$} & Neighb. & Genetic & LES (Dyn.) & Cart. & WT & $\mathrm{c}$ \\
\hline Foroutan et al. (2018) & [9] & Building & Genetic & ELES (Dyn.) & Un-Str & WT & $\mathrm{a}, \mathrm{c}$ \\
\hline Gao et al. (2018) & {$[15]$} & Neighb. & Real & $\begin{array}{c}\text { RANS (SKE, RNG, } \\
\text { RKE) }\end{array}$ & Un-Str. & Field & $\mathrm{b}, \mathrm{c}$ \\
\hline Cui et al. (2017) & {$[10]$} & Building & Genetic & $\begin{array}{c}\text { RANS (SKE, RNG, } \\
\text { RKE) }\end{array}$ & Str. & WT & $\mathrm{a}, \mathrm{b}$ \\
\hline Hong et al. (2017) & {$[21]$} & Neighb. & Genetic & RANS (SKE) \& Rgdf. & Un-Str. & Field & $\mathrm{c}$ \\
\hline Azizi et al. (2017) & {$[22]$} & Neighb. & Genetic & RANS (SKE) & Un-Str. & - & $\mathrm{c}$ \\
\hline Antoniou et al. (2017) & {$[23]$} & Neighb. & Genetic & $\begin{array}{c}\text { RANS (RKE) \& LES } \\
\text { (Dyn.) }\end{array}$ & Un-Str. & WT & $\mathrm{c}, \mathrm{d}$ \\
\hline Miguel et al. (2017) & {$[24]$} & Building & Genetic & $\begin{array}{c}\text { RANS (SKE, RNG, } \\
\text { RKE) } \\
\end{array}$ & Struct. & WT & $\mathrm{c}$ \\
\hline Chen et al. (2017) & {$[25]$} & Neighb. & Genetic & RANS (SKE) & Struct. & WT & $\mathrm{c}$ \\
\hline Hang et al. (2017) & {$[26]$} & Street & Genetic & RANS (RNG) & Struct. & WT & $\mathrm{c}$ \\
\hline Badas et al. (2017) & {$[16]$} & Street & Genetic & RANS (SKE) & Struct. & Field & $\mathrm{b}, \mathrm{c}$ \\
\hline bDave et al. (2017) & {$[11]$} & City & Real & RANS (SKE) & Un-Str. & - & $\mathrm{a}, \mathrm{b}$ \\
\hline Kubilay et al. (2017) & {$[30]$} & Street & Genetic & RANS (SKE) & Str. & Field & $\mathrm{c}, \mathrm{d}$ \\
\hline You et al. (2017) & {$[27]$} & $\begin{array}{l}\text { Building \& } \\
\text { Neighb. }\end{array}$ & Genetic & RANS (SKE) & Str. & WT & $\mathrm{c}$ \\
\hline Zhang et al. (2016) & {$[17]$} & Building & Genetic & WIFFA \& NJU-RWM & - & WT & $\mathrm{b}, \mathrm{c}$ \\
\hline Cui et al. (2016) & {$[18]$} & $\begin{array}{c}\text { Neighb. \& } \\
\text { Street \& Indoor }\end{array}$ & Genetic & RANS (SKE, RKE) & Str. & WT & $\mathrm{b}$ \\
\hline Park et al. (2016) & {$[28]$} & Street & Genetic & RANS (SKE, RKE) & Struct. & WT & $\mathrm{c}$ \\
\hline Cammelli et al. (2016) & [29] & City & Real & RANS (RKE) & Un-Str. & WT & $\mathrm{c}$ \\
\hline Ying et al. (2016) & {$[19]$} & Building & Genetic & RANS (SKE) & Str. & Field & $\mathrm{b}$ \\
\hline Mccarty et al. (2015) & {$[12]$} & Country & - & Stat. & - & - & $\mathrm{a}, \mathrm{c}$ \\
\hline
\end{tabular}

Neighb. $=$ Neighborhood scale,

Real. $=$ Realistic, $\mathrm{WT}=$ Wind-tunnel measurements, Field $=$ Field measurements,

Struct. $=$ Structural grid, Un-Struct. $=$ Unstructured grid, Cart. $=$ Cartesian grid,

RANS $=$ Reynolds-averaged Navier-Stokes, RKE $=$ Realizable $\mathrm{k}-\varepsilon$ model, SKE $=$ Standard $\mathrm{k}-\varepsilon$ model, $\mathrm{RNG}=$ Renormalization Group k- $\varepsilon$ model, LES = Large Eddy Simulation, ELES = The embedded Large Eddy Simulation, Dyn. = Dynamic SmagorinskyLilly SGS model, SSTKO = SST k- $\omega$ model, Rgdf. = Revised generalized drift flux model, WIFFA = Wind information field fast analysis model, NJU-RWM = Nanjing University random-walk dispersion model, Stat. $=$ Statistical models, ADMS Urban $=$ Operational air-quality model, $\mathrm{WRF}=$ Weather research and forecasting model, URBAIR $=$ Urban air quality system, $\mathrm{AD}=\mathrm{Advection}-$ diffusion (AD) method.

The entry "Focus" refers to different aspects that were investigated in each study, which are:

a. Study on relationship between urban wind field and pollutant diffusion

b. Study on the relationship between wind and pollutant diffusion at different scales (from city to single building)

c. Study on the relationship between wind, pollutant concentration and urban form (macro to micro)

d. Study on new evaluation index of ventilation efficiency 
Table 2. Existing quantitative indicators of urban ventilation.

\begin{tabular}{|c|c|c|c|c|}
\hline Indicator & Study & Ref. & Focus & Application scale \\
\hline Air delay & Antoniou et al. (2017) & {$[23]$} & Duration & Outdoor environment \\
\hline Age of air & Hang et al. (2011) & {$[32]$} & Duration & Indoor \& outdoor environments \\
\hline Air exchange rate & Xie et al. (2006) & {$[33]$} & Exchanging air & Indoor \& outdoor environments \\
\hline Urban breathability & Neophytou et al. (2005) & {$[34]$} & Exchanging air & Outdoor environment \\
\hline $\begin{array}{c}\text { Pollutant exchange rate } \\
\text { Pollutant-exchange } \\
\text { velocity }\end{array}$ & $\begin{array}{c}\text { Luccolieri et al. (2015) } \\
\text { Liu et al. (2005) }\end{array}$ & $\begin{array}{c}{[36]} \\
\text { Cheng et al. (2008) }\end{array}$ & $\begin{array}{c}\text { Pollutant concentration } \\
\text { distribution }\end{array}$ & Indoor \& outdoor environments \\
\hline Exchange velocity & Bentham and Britter (2003) & {$[31]$} & Rate of contaminant removal \\
\hline
\end{tabular}

will become the most detrimental health issue among urban populations.

How to improve urban air quality should be considered in the urban planning period. Urban layout design considering annual or seasonal wind directions has been performed for many cities. Less pollutant accumulation and more efficient pollutant dispersion could be the design objects of urban planning on the issues of air quality. It is known that the airflow structure determines the distribution of pollutants. Many studies on the dispersion of air pollutants in urban areas begin with the investigation of the airflow characteristics [3-5]. Under the assumption of unchanged pollution sources, effective ventilation has become an important way to improve urban air quality.

In recent years, there have been some important results for the research on the correlation between pollutant dispersion and wind environment, as shown in Table 1. It includes the research methods of the relationship between pollutant diffusion and wind environment [6-12], the influence of wind on urban pollution diffusion at various scales [13-19], the relationship between wind, pollutant diffusion and urban scale layout [20-29], and the establishment of new ventilation efficiency evaluation index [30]. From these studies, the following conclusions can be drawn:

(1) CFD method is widely used in the study of the relationship between wind and pollutant diffusion. RANS is the main model used. Transport based recurrence CFD (rCFD) and LES method are also tried in the studies, and become more and more accurate. Considering the computational efficiency and time cost, RANS model is used for simulation in the current study.

(2) These studies cover a series of scales from macro to micro. According to the classification from Britter and Hanna [31], the scales include urban, neighborhood, street, and building scales. A coarser geometric model is usually employed for a larger research scale, containing only the basic geometric information. Unstructured grids are generally employed for urban, neighborhood, and street scales, and structural grids are often used for the building scale.
(3) Most scholars have focused on the influence of the urban design factors on the pollutant dispersion at different scales, and have concluded that different design factors lead to different airflows and different pollutant distributions. However, there are few studies on how to improve the urban ventilation effects by changing and adjusting design factors. Previous methods have led to many achievements but need further steps for the final optimizations.

(4) As shown in Table 2, existing quantitative indicators include air delay [23], air age [32], Urban breathability [33], Pollutant exchange rate [34-35] and Pollutant-exchange velocity [36-38]. These studies provide effective references for the quantitative evaluation of urban air quality, but their characteristic parameters are time or concentration, which are not directly related to the components of wind environments. Therefore, they are not suitable for the evaluation of air quality under urban wind environment to perform further optimization. It is necessary to introduce a new indicator from wind environment components as main characteristics.

A more intuitive estimation for ventilation or air quality in urban planning is the sum of urban areas with stronger wind. Continuous wind is always able to diffuse air pollutant. Wind speed can be used as an indicator for pollutant dispersion efficiency. Strong wind brings clean air rapidly. Weak wind brings clean air slowly. If the wind speed is too small, it will take very long time to diffuse all the air pollutant. In this situation, the low speed wind can be defined as "static wind". Traditionally, the static wind is defined as a meteorological condition in which the average wind speed $U_{z=10 \mathrm{~m}}$ is less than $0.5 \mathrm{~m} / \mathrm{s}$ at the height of 10 $\mathrm{m}$ above the ground. This is probably not suitable on the aspect of pollutant dispersion efficiency. The static wind condition should be redefined by comparing and analyzing the air pollutant dispersion processes under different wind speeds.

The main objective of this study is to evaluate a proper value for static wind speed on the aspect of pollutant dispersion efficiency. The static wind 
condition is redefined by comparing and analyzing the air pollutant dispersion processes under different wind speeds. The air pollutant dispersion processes are simulated through a series of unsteady Reynoldsaveraged Navier-Stokes (RANS) simulations with validated CFD methods. The variation of pollutant concentration with time is obtained and analyzed, which is the essential basic data for evaluating the static wind speed. It is expected that the present results will provide some reference guidance for urban designs based on the relationship between wind environment and air pollutant dispersion.

\section{CFD Methods}

\section{The Governing Equations}

The pollutant concentration in the air is the main index to evaluate the air quality. Effective dispersion of pollutants is an effective way to improve air quality. Pollutant dispersion can be treated as multi-species fluid flow which is governed by compressible real gas NavierStokes equations as follows:

$$
\frac{\partial \boldsymbol{Q}}{\partial t}+\frac{\partial \boldsymbol{F}_{i}}{\partial \boldsymbol{x}_{i}}-\frac{\partial \boldsymbol{G}_{i}}{\partial \boldsymbol{x}_{i}}=\boldsymbol{\xi}
$$

...where $\boldsymbol{Q}$ is the dependent variable vector, $\boldsymbol{F}_{i}$ is the inviscid flux vectors, $\boldsymbol{G}_{i}$ is the viscous flux vectors, and $S^{\&}$ is the source term vector. These are given as:

$$
\boldsymbol{Q}=\left[\begin{array}{c}
\rho \\
\rho \boldsymbol{u}_{i} \\
e \\
\rho \sigma_{1} \\
\mathrm{M} \\
\rho \sigma_{N-1}
\end{array}\right], \quad \boldsymbol{F}_{i}=\left[\begin{array}{c}
\rho \boldsymbol{u}_{i} \\
\rho \boldsymbol{u}_{i} \boldsymbol{u}_{j}+p \delta_{i j} \\
\boldsymbol{u}_{i}(e+p) \\
\rho \boldsymbol{u}_{i} \sigma_{1} \\
\mathrm{M} \\
\rho \boldsymbol{u}_{i} \sigma_{N-1}
\end{array}\right], \quad \boldsymbol{G}_{i}=\left[\begin{array}{c}
0 \\
\tau_{i j} \\
\boldsymbol{u}_{k} \tau_{k i}-\boldsymbol{q}_{i} \\
\rho D \partial \sigma_{1} / \partial \boldsymbol{x}_{i} \\
\mathrm{M} \\
\rho D \partial \sigma_{N-1} / \partial \boldsymbol{x}_{i}
\end{array}\right]
$$

...where $\rho$ is the density, $p$ is the pressure, $e$ is the total energy, $\boldsymbol{u}_{i}$ is the velocity components in the $\boldsymbol{x}_{i}$ direction and $\sigma_{i}$ is the mass fraction of species $i$. The species diffusion term is already written by assuming Fick's law of binary diffusion which states that all species diffuse into one another in an equal way. Thus giving rise to single diffusivity constant, $D$. The stresses and strains $\tau_{i j}$ are linearly related for Newtonian fluid and $\boldsymbol{q}_{i}$ can be written from Fourier's law of conduction.

However, wind speed in atmospheric environment is usually not high enough to be directly solved by compressible Navier-Stokes equations. The preconditioned equation system must be employed to reduce stiffness by moderating the eigenvalue spread caused by low wind speed. This can accelerate convergence in low-speed flows and reduce the inherent level of artificial dissipation associated with the spatial discretization scheme.
In preconditioning, the $\partial \boldsymbol{Q} / \partial t$ term is multiplied by the inverse of the preconditioning matrix $\boldsymbol{P}^{-1}$, thus altering the eigenvalues of the hyperbolic system. The usually used preconditioning matrix and its inverse from Turkel can be written as:

$$
\begin{gathered}
\boldsymbol{P}=\left[\begin{array}{ccccc}
\frac{c^{2}}{\beta^{2} M a_{r}^{2}} & 0 & 0 & 0 & \delta \\
\frac{\varepsilon u_{1}}{\rho \beta^{2} M a_{r}^{2}} & 1 & 0 & 0 & 0 \\
\frac{\varepsilon u_{2}}{\rho \beta^{2} M a_{r}^{2}} & 0 & 1 & 0 & 0 \\
\frac{\varepsilon u_{3}}{\rho \beta^{2} M a_{r}^{2}} & 0 & 0 & 1 & 0 \\
0 & 0 & 0 & 0 & 1
\end{array}\right], \\
\boldsymbol{P}^{-1}=\left[\begin{array}{ccccc}
\frac{\beta^{2} M a_{r}^{2}}{c^{2}} & 0 & 0 & 0 & -\frac{\beta^{2} M a_{r}^{2}}{c^{2}} \delta \\
-\frac{\varepsilon u_{1}}{\rho c^{2}} & 1 & 0 & 0 & \frac{\varepsilon u_{1}}{\rho c^{2}} \delta \\
-\frac{\varepsilon u_{2}}{\rho c^{2}} & 0 & 1 & 0 & \frac{\varepsilon u_{2}}{\rho c^{2}} \delta \\
-\frac{\varepsilon u_{3}}{\rho c^{2}} & 0 & 0 & 1 & \frac{\varepsilon u_{3}}{\rho c^{2}} \delta \\
0 & 0 & 0 & 0 & 1
\end{array}\right]
\end{gathered}
$$

...where $c$ is local sound speed, $\beta M a_{r}$ is related to local Mach number, and different value of $\delta$ and $\varepsilon$ leads to different preconditioning matrix. For example, if $\delta=1$ and $\varepsilon=0, \boldsymbol{P}$ is the Choi-Merkle preconditioning matrix; if $\delta=0$ and $\varepsilon=1, \boldsymbol{P}$ is the Weiss-Smith preconditioning matrix. In order to avoid the singularity of the preconditioning matrix near the stagnation point, $\beta M a_{r}$ can be written as:

$$
\beta^{2} M a_{r}^{2}=\min \left\{\max \left[K_{1} c^{2} M a^{2}\left(1+\frac{1-M a_{0}^{2}}{M a_{0}^{4}} M a^{2}\right), K_{2}^{2} U_{\infty}^{2}\right], c^{2}\right\}
$$

Here, $K_{1}$ and $K_{2}$ are free parameters and both of them can be given the value of 1.0. Ma is the preset reference Mach number and it is usually set to 0.6 .

\section{The Turbulence Model}

To solve the governing equations efficiently, the Navier-Stokes equations need to be averaged and become the RANS equations, which govern the mean flow. The RANS equations need to be closed by modeling the Reynolds stress term $R_{i j}=-\rho \overline{\boldsymbol{u}_{i}^{\prime} \boldsymbol{u}_{j}^{\prime}}$ through a turbulence model. The two-equation realizable $k-\varepsilon$ model is chosen in the present work.

In realizable $k-\varepsilon$ model, the Boussinesq relation is used to obtain Reynolds-stresses algebraically from the modeled eddy viscosity and the available mean-strain tensor. The model consists of the following transport equations for the turbulence kinetic energy $k$ and its dissipation rate $\varepsilon$ : 


$$
\begin{gathered}
\frac{\partial}{\partial t}(\rho k)+\frac{\partial}{\partial x_{i}}\left(\rho k \boldsymbol{u}_{i}\right)=\frac{\partial}{\partial \boldsymbol{x}_{i}}\left[\left(\mu+\frac{\mu_{\mathrm{t}}}{\sigma_{k}}\right) \frac{\partial k}{\partial \boldsymbol{x}_{i}}\right]+P_{k}-\rho \varepsilon \\
\frac{\partial}{\partial t}(\rho \varepsilon)+\frac{\partial}{\partial \boldsymbol{x}_{i}}\left(\rho \varepsilon \boldsymbol{u}_{i}\right)=\frac{\partial}{\partial \boldsymbol{x}_{i}}\left[\left(\mu+\frac{\mu_{\mathrm{t}}}{\sigma_{\varepsilon}}\right) \frac{\partial \varepsilon}{\partial \boldsymbol{x}_{i}}\right]+\left(C_{\varepsilon 1} P_{k}-C_{\varepsilon 2} \rho \varepsilon+E\right) T_{t}^{-1}
\end{gathered}
$$

Here, $P_{k}$ is the rate of production of turbulence energy, $T_{t}$ is a realizable estimate of the turbulence timescale, and $E$ is an additional term in the dissipation rate equation and it is designed to improve the model response to adverse pressure-gradient flows. They are given by:

$$
\begin{gathered}
P_{k}=-\rho \overline{\boldsymbol{u}_{i}^{\prime} \boldsymbol{u}_{j}^{\prime}} \frac{\partial \boldsymbol{u}_{i}}{\partial \boldsymbol{x}_{j}} \\
\rho \overline{\boldsymbol{u}_{i}^{\prime} \boldsymbol{u}_{j}^{\prime}}=\frac{2}{3} \rho k \delta_{i j}-\mu_{\mathrm{t}}\left(\frac{\partial \boldsymbol{u}_{i}}{\partial \boldsymbol{x}_{j}}+\frac{\partial \boldsymbol{u}_{j}}{\partial \boldsymbol{x}_{i}}-\frac{2}{3} \frac{\partial \boldsymbol{u}_{k}}{\partial \boldsymbol{x}_{k}} \delta_{i j}\right), \\
T_{t}=\frac{k}{\varepsilon} \max \left\{1, \zeta^{-1}\right\}, \zeta=\sqrt{\operatorname{Re}_{t} / 2}, \operatorname{Re}_{t}=\rho k^{2} /(\mu \varepsilon) \\
E=A_{E} \rho \sqrt{\varepsilon T_{t}} \Psi \max \left\{k^{\frac{1}{2}},(v \varepsilon)^{\frac{1}{4}}\right\}, \Psi=\max \left\{\frac{\partial k}{\partial \boldsymbol{x}_{i}} \frac{\partial \tau}{\partial \boldsymbol{x}_{i}}, 0\right\}, \\
\tau=k / \varepsilon
\end{gathered}
$$

...where, $\quad C_{\mu}=0.09, \quad C_{\varepsilon 1}=1.44, \quad C_{\varepsilon 2}=1.92, \quad \sigma_{k}=1.0$, $\sigma_{\varepsilon}=1.3, A_{E}=0.3$.

\section{Description of Numerical Algorithms}

Three-dimensional RANS equations are solved based on finite volume method using second-order discretization. The backward Euler implicit scheme is used for time integration to maintain better stability during the solution. Dual time-stepping is also employed to solve unsteady RANS equations for transient simulations. Multi-grid acceleration technology and the automatic Courant-Friedrichs-Lewy (CFL) number adjustment procedure are introduced to improve computational efficiency through user-defined functions. The realizable $k-\varepsilon$ turbulence model is employed for current numerical simulations. Multi-species simulations are performed by solving the real gas RANS equations with the mass fraction of every species. Corresponding additional equations are introduced for the pollutant dispersion simulations. The laminar Schmidt number is set to 0.7 in the multi-species simulations.

\section{CFD Simulation Settings}

\section{Computational Grid}

The computational grid is generated using ANSYS ICEM CFD (version 16.1) following the recommended guidelines from [39] and [40]. The computational domain is discretized into hexahedral elements through structure blocking function in ICEM CFD. The grid resolution is finer near the solid wall boundary such as building and ground, which is achieved by covering $\mathrm{O}$-grid on these surfaces. The volume ratio between two consecutive cells is controlled not higher than 1.2. The height of the first cell off the wall is set to $1 \mathrm{~mm}$, corresponding to $y^{+} \sim O(1)$. The grid sensitivity analysis should be performed to verify the influence of the grid size on CFD simulations.

\section{Boundary Conditions}

Non-slip wall boundary condition is imposed on the solid wall boundaries including ground surfaces, building surfaces and wind tunnel wall surfaces. Symmetry boundary condition is defined at the top and lateral boundaries of the computational domain except for internal flow simulations such as flow in wind tunnel. Zero-gradient outflow boundary condition is used at the outlet of the computational domain.

For the inflow boundary condition, a logarithmic portion of a fully turbulent boundary layer is introduced to define the inflow profiles with the consideration of the atmospheric boundary layer [41]:

$$
U=\frac{U^{*}}{\kappa} \ln \left(1+\frac{z}{z_{0}}\right), \quad k=\frac{U^{* 2}}{\sqrt{C_{\mu}}} \quad \varepsilon=\frac{U^{* 3}}{\kappa\left(z+z_{0}\right)}
$$

...where $U^{*}=\sqrt{\tau / \rho}$ is the friction speed (square root of the ratio of turbulence shear-stress and density of air), $z$ is the vertical coordinate off the ground, $z_{0}$ is the roughness length, $\kappa=0.41$, and $C_{\mu}=0.09$.

\section{Validation and Verification}

To validate the present numerical methods, the case from the wind tunnel experiments by Davidson et al. [42] are simulated and examined by the comparison between numerical results and experimental measurements. The staggered building array configuration in the experiment is shown in Fig. 1. The building array consists of 39 obstacles with dimensions of $\mathrm{H}$ (height) $=\mathrm{W}$ (width) $=\mathrm{B}($ breadth $)=0.12 \mathrm{~m}$. The distance between the obstacles is twice the relevant obstacle dimension, that is $0.24 \mathrm{~m}$ in both the streamwise $(x)$ and spanwise $(y)$ directions and, therefore, the spanwise aspect ratio of the array is 19 and the streamwise aspect ratio is 16 . The point source is located at $10 \mathrm{~B}$ in front of building array according to the experiment.

The computational grid is illustrated in Fig. 2 with $\mathrm{X}$ in range [-150B, 225B], $\mathrm{Y}$ in range [-160W, 160W], and $\mathrm{Z}$ in range $[0,100 \mathrm{H}]$. Three set of grids are generated to perform grid independence test with cell number of $649,109,2,110,976$, and 7,175,061, corresponding to coarse grid, medium grid and fine 


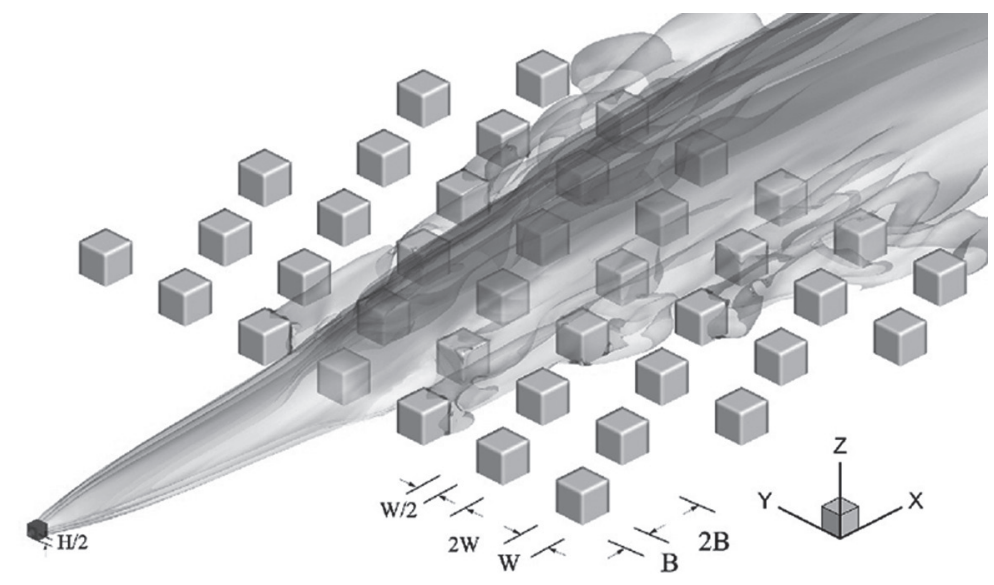

Fig. 1. A schematic diagram of staggered building arrays simulated in this study from Davidson's experiments. The building array consists of 39 gray obstacles. The source is the point in front of the building array.

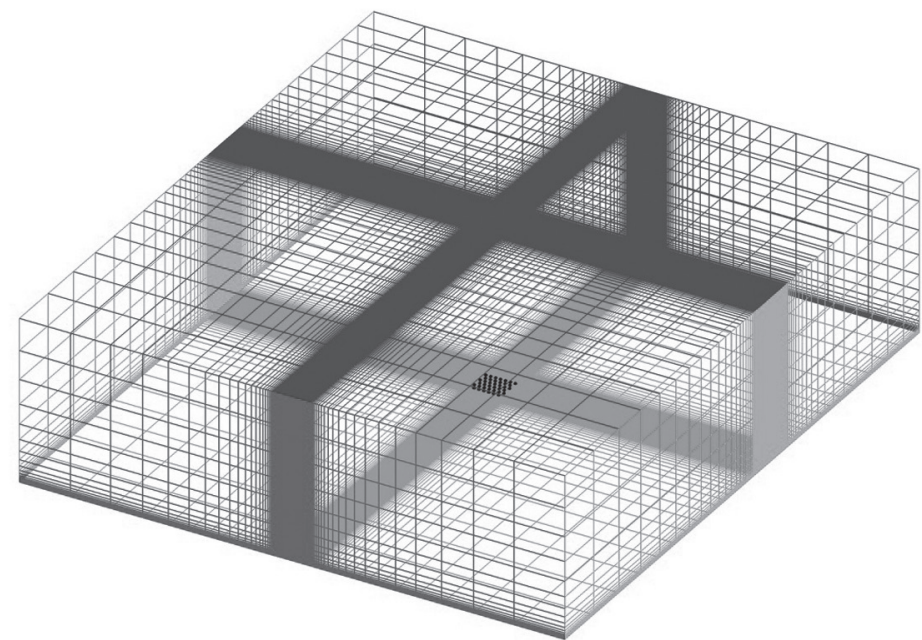

Fig. 2. Computational grid of the building array, with different surfaces representing different boundary conditions.

grid. The non-dimensional time step is 0.05 . The steady RANS simulations are performed first to provide suitable initial data for unsteady RANS simulations. The validation case is computed on a 16-core node (AMD Ryzen 71700 Eight-Core Processor @3.00 GHz) PC with 16 GB system memory. The spatial ( $y$-direction) and temporal average of the U-component of mean velocity at $z=\mathrm{H} / 2$ are presented in Fig. 3a) from experimental results to the three CFD simulation results. Fig. 3b) gives the horizontal mean-concentration profiles at $z=\mathrm{H} / 2$ behind the fifth row. It can be seen from these two figures that the mean numerical results are in fairly good agreement with the experimental data. The dash lines (coarse grid) are a little different from solid lines (medium grid) and dash dot lines (fine grid). The solid lines and dash dot lines almost coincide. Therefore, the medium grid is fine enough to obtain grid independent results.

The vertical and lateral profiles of the U-component of mean velocity at $z=\mathrm{H} / 2$ are shown in Fig. 4a) and b). The CFD results are computed using medium grid and agree well with the measured experimental results. Therefore, according to the comparisons in the four figures, the present CFD method is suitable for contaminant dispersion simulations in complex building environments.

\section{Results and Discussion}

\section{Air Pollutant Dispersion Model}

To find out the critical static wind speed according to the air pollutant dispersion efficiency, a sample idealized air pollutant dispersion model is established and simulated. The idealized model consists of the ground with $100 \mathrm{~m}$ breadth and $100 \mathrm{~m}$ width, the polluted air above the ground with $100 \mathrm{~m}$ height, and the clean air at the entrance with the inflow profile according to Equation (10). The surface roughness of the 
a)

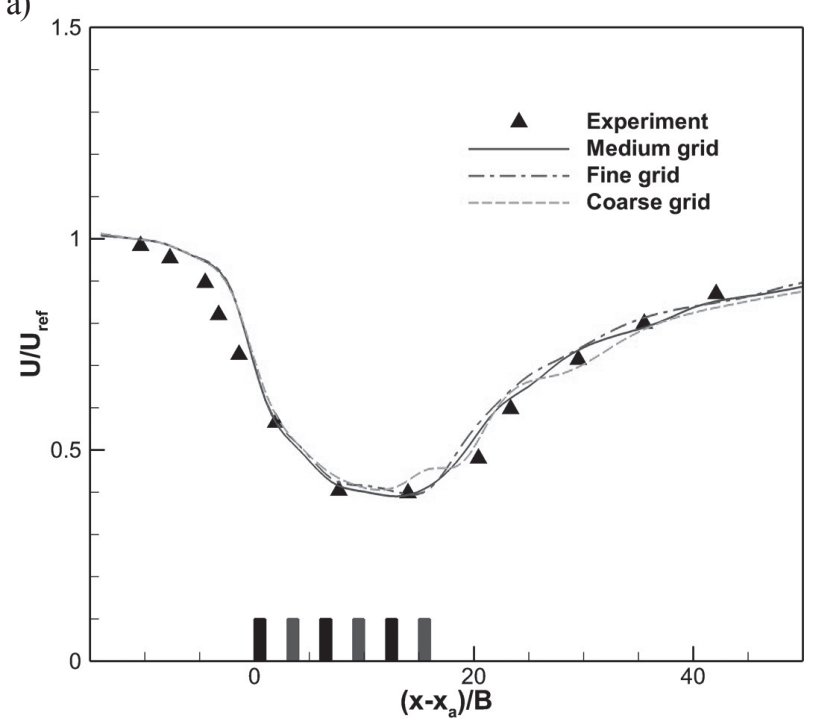

b)

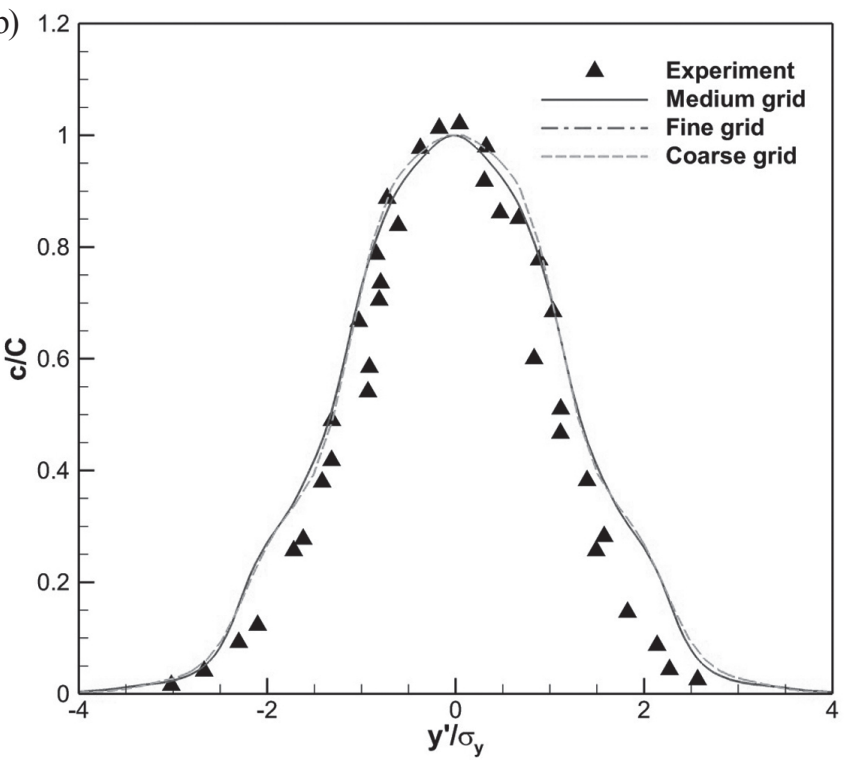

Fig. 3. Grid sensitivity analysis: a) Spatial (y-direction) and temporal average of the U-component of mean velocity measured at $\mathrm{z}=$ $\mathrm{H} / 2$. $U_{\text {ref }}$ is the magnitude of the velocity at $\left(x-x_{a}\right) / B=-16$. b) Horizontal mean-concentration profiles from plumes passing through the building array. Note: $\mathrm{c}$ is mean concentration; $\mathrm{C}$ is the maximum centerline mean concentration; is the lateral spread; $\mathrm{y}^{\prime}=\mathrm{y}-\mathrm{y}_{\mathrm{cl}}$ and $\mathrm{y}_{\mathrm{cl}}$ is the distance to the centerline of the plume; $\sigma_{y}$ is the lateral spread of the plume.

ground is defined as $z_{0}=0.001 \mathrm{~m}$. The computational domain is an idealized cube with length of $100 \mathrm{~m}$. The computational grid is generated using ANSYS ICEM CFD following the guidelines in the previous sections. The grid contains 1 million hexahedral cells with higher resolution near the ground and entrance as shown in Fig. 5.

For multi-species simulation, the time-dependent three-dimensional real gas RANS equations are solved using realizable $k$ - $\varepsilon$ turbulence model. Three species are considered in the simulations, including air, $\mathrm{SO}_{2}$, and $\mathrm{NO}_{2}$. The mass fraction of $\mathrm{SO}_{2}$ and $\mathrm{NO}_{2}$ are $2.139 \times 10^{-6}$ and $7.673 \times 10^{-7}$ respectively, corresponding to the situation of $I A Q I$ (individual air quality index) $=500$ in Table 3 according to the 24 hour mean concentrations of the pollutants. The IAQI can be calculated from individual pollutant concentration using the following equation: a)

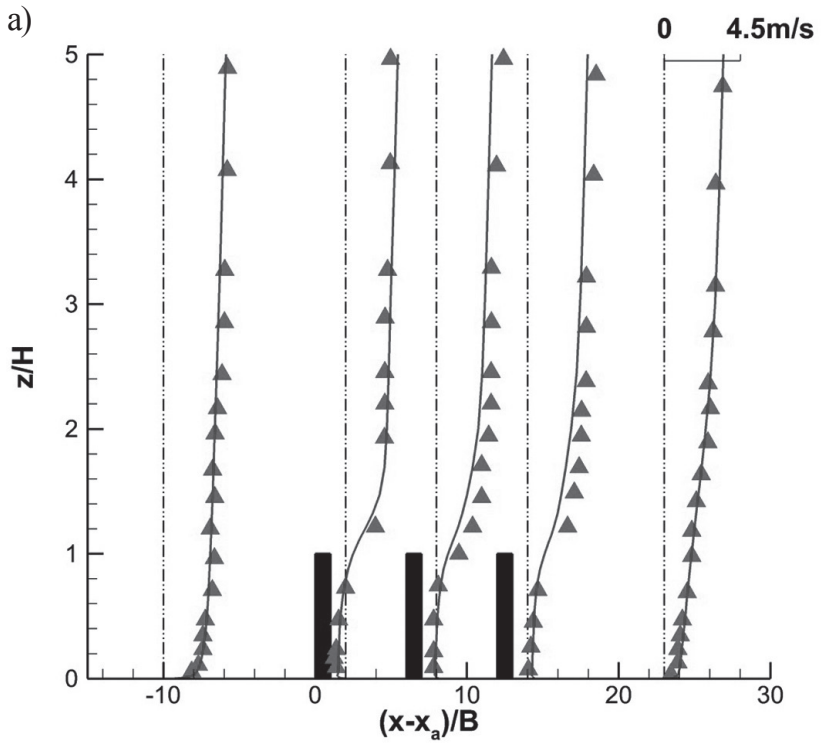

b)

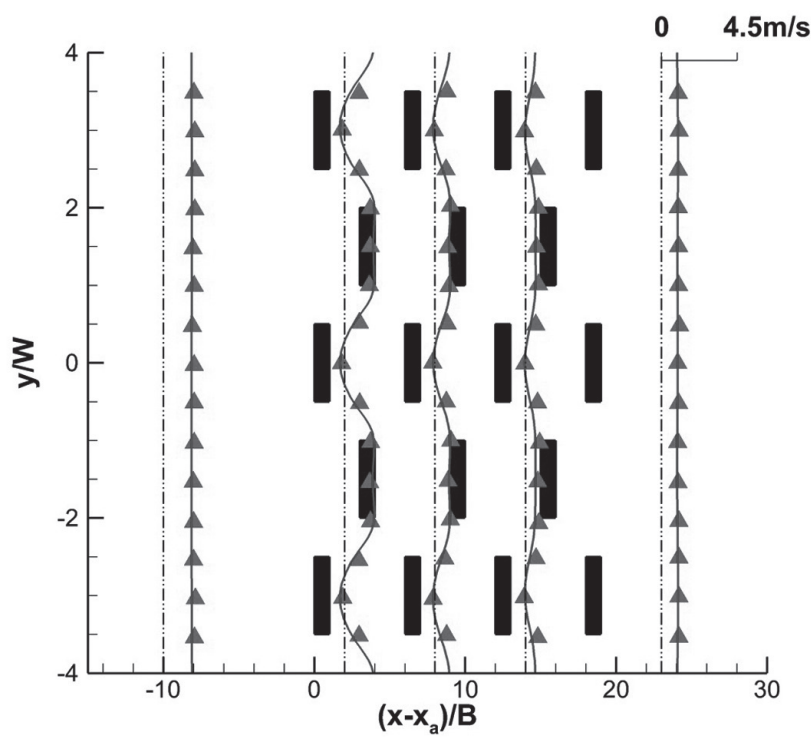

Fig. 4. U-component profiles of mean velocity: Triangle, experimental data; Line, numerical data; Black area, the building. a) Vertical profiles of the U-component of mean velocity along the $\mathrm{x}$-axis of the building array. b) Lateral profiles of the U-component of mean velocity at $\mathrm{z}=\mathrm{H} / 2$. Note that $\mathrm{xa}$ is the downstream distance from the source to the front face of the building array. 


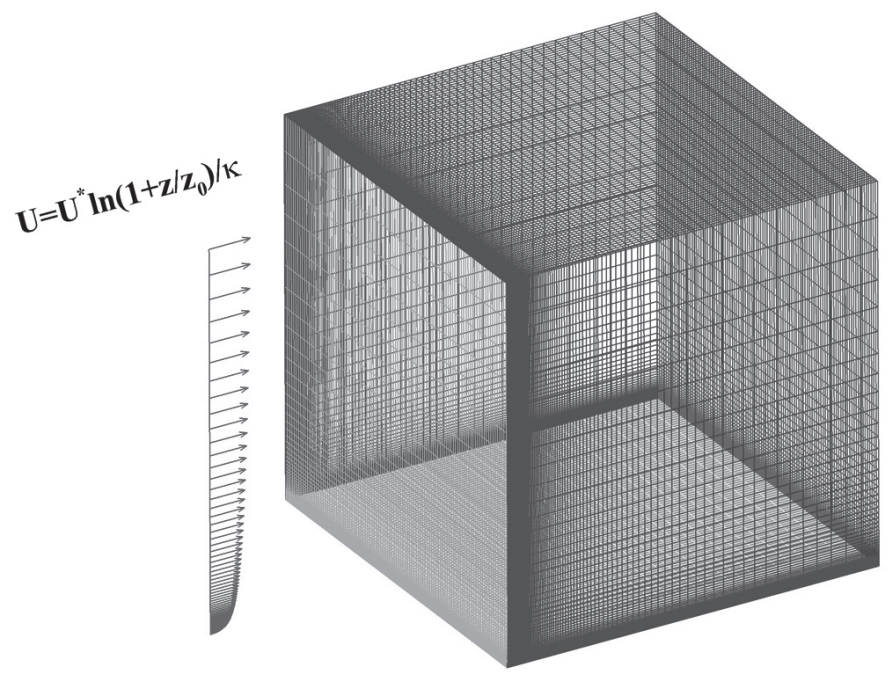

Fig. 5. The simple idealized air pollutant dispersion model and its computational grid for CFD simulation of air pollutant dispersion.

Table 3. Individual air quality index and the corresponding concentrations of $\mathrm{SO}_{2}$ and $\mathrm{NO}_{2}$.

\begin{tabular}{|c|c|c|c|c|}
\hline$I A Q I$ & $\begin{array}{c}\mathrm{SO}_{2}, 24 \text { hour Mean } \\
\left(\mu \mathrm{g} / \mathrm{m}^{3}\right)\end{array}$ & $\begin{array}{c}\mathrm{SO}_{2}, \text { hourly mean } \\
\left(\mu \mathrm{g} / \mathrm{m}^{3}\right)\end{array}$ & $\begin{array}{c}\mathrm{NO}_{2}, 24 \text { hour Mean } \\
\left(\mu \mathrm{g} / \mathrm{m}^{3}\right)\end{array}$ & $\begin{array}{c}\mathrm{NO}_{2}, \text { hourly mean } \\
\left(\mu \mathrm{g} / \mathrm{m}^{3}\right)\end{array}$ \\
\hline 0 & 0 & 0 & 0 & 0 \\
\hline 50 & 50 & 150 & 40 & 200 \\
\hline 100 & 150 & 500 & 180 & 700 \\
\hline 150 & 475 & 650 & 280 & 1200 \\
\hline 200 & 800 & 800 & 565 & 2340 \\
\hline 300 & 1600 & - & 750 & 3090 \\
\hline 400 & 2100 & - & 940 & 3840 \\
\hline 500 & 2620 & - & & 30 \\
\hline
\end{tabular}

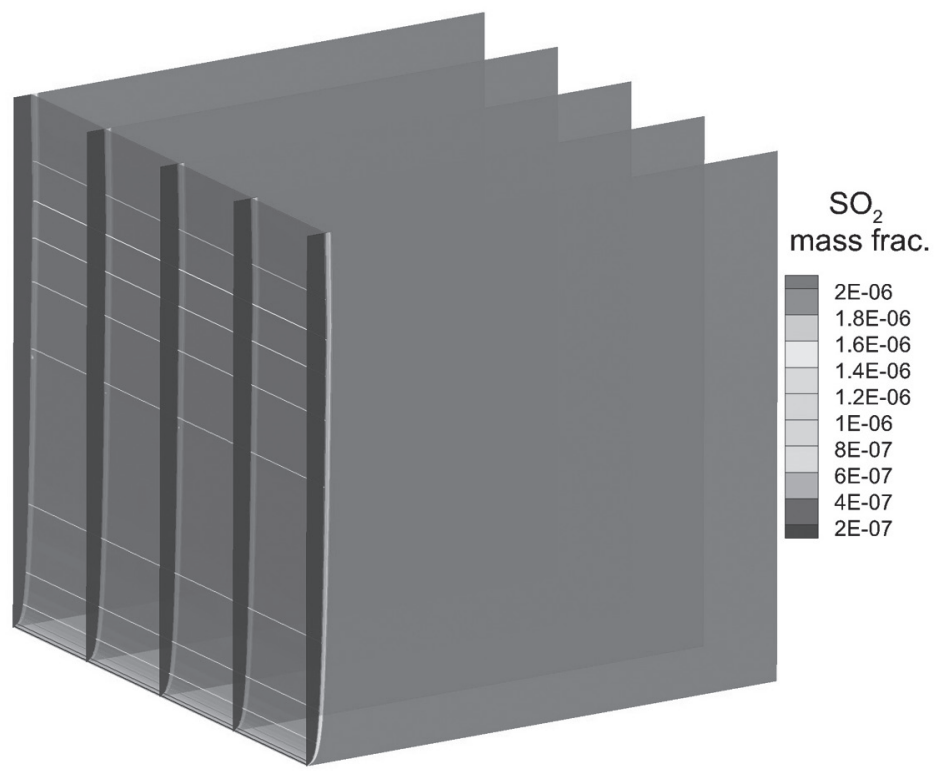

Fig. 6. The mass fraction of $\mathrm{SO}_{2}$ for the scenario of $\mathrm{U}_{\mathrm{z}=1.5 \mathrm{~m}}=3.0 \mathrm{~m} / \mathrm{s}$ at $\mathrm{t}=1.0 \mathrm{~s}$ on XZ plane slices. 
a)

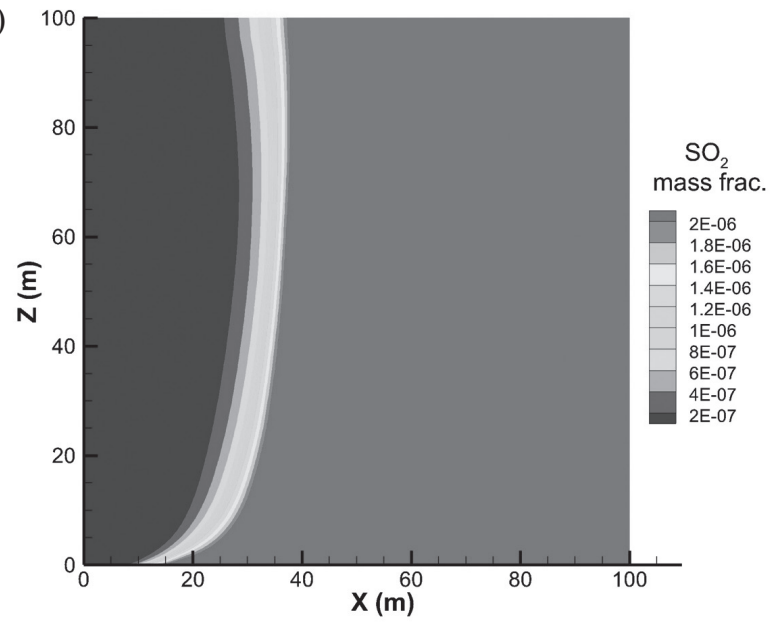

c)

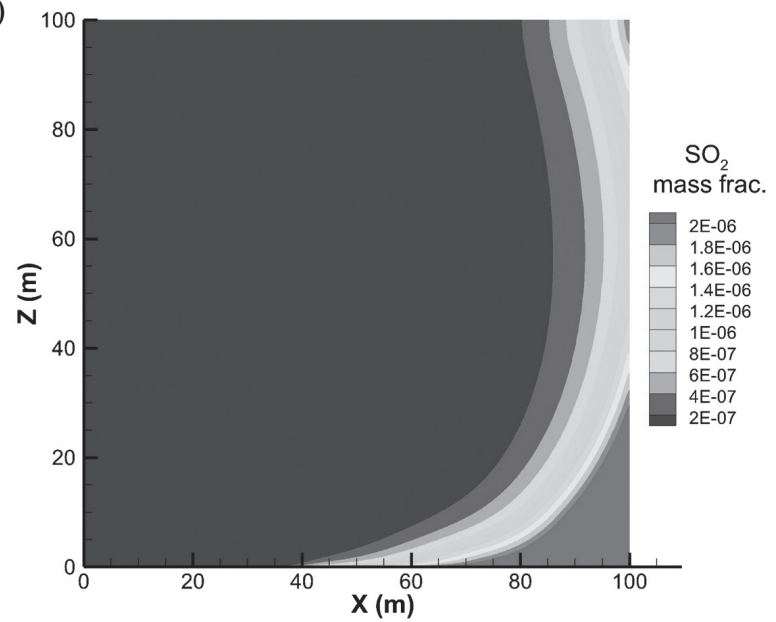

b)

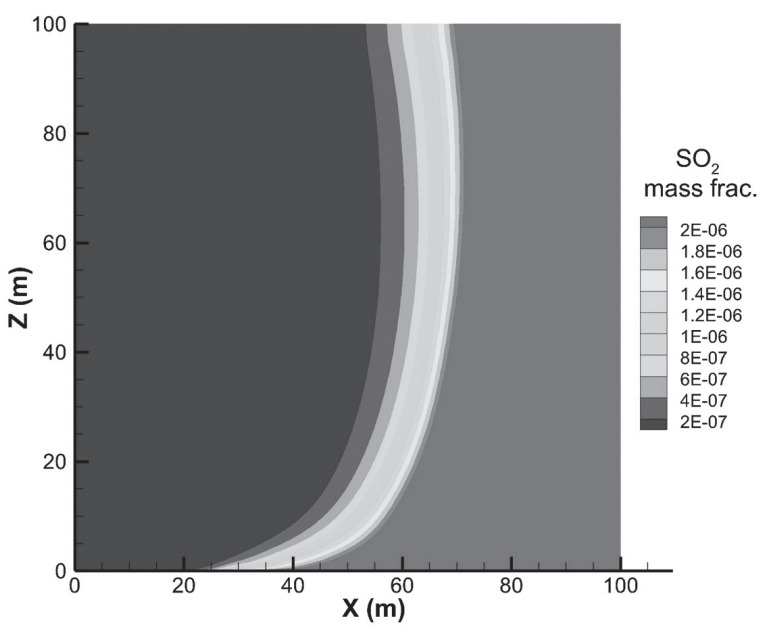

d)

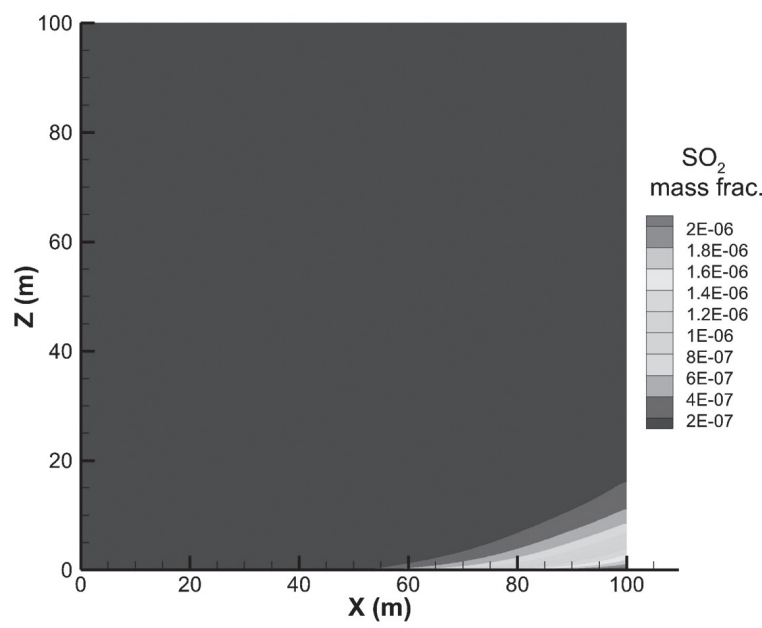

Fig. 7. The $\mathrm{SO}_{2}$ dispersion at different time in the middle XZ plane. a) $\left.\left.\left.\mathrm{t}=5.0 \mathrm{~s} ; \mathrm{b}\right) \mathrm{t}=10.0 \mathrm{~s} ; \mathrm{c}\right) \mathrm{t}=15.0 \mathrm{~s} ; \mathrm{d}\right) \mathrm{t}=20.0 \mathrm{~s}$.

$$
I A Q I=\frac{I_{\text {high }}-I_{\text {low }}}{C_{\text {high }}-C_{\text {low }}}\left(C-C_{\text {low }}\right)+I_{\text {low }}
$$

...where, $C$ is the pollutant concentration, $C_{\text {low }}$ is the concentration breakpoint that is $\leq C, C_{\text {high }}$ is the concentration breakpoint that is $\geq C, I_{\text {low }}$ is the index breakpoint corresponding to $C_{\text {low }}$, and $I_{\text {high }}$ is the index breakpoint corresponding to $C_{h i g h}$.

For time integration, a dual time-stepping via second-order backward Euler implicit scheme with a fixed global time-step is employed. The time-step $\Delta \mathrm{t}$ is set to $0.001 \mathrm{~s}$ and 10 internal iterations are executed for each global step. The CFL number is ramped from 1 to 100 during the first 200 global time steps to obtain an efficient and robust CFD computation. The global time is set to $\mathrm{L}_{x} / \mathrm{U}_{\mathrm{z}=1.5 \mathrm{~m}}$, where $\mathrm{L}_{x}$ is the streamwise length of the computational domain, and $\mathrm{U}_{\mathrm{z}=1.5 \mathrm{~m}}$ is the wind speed at a $1.5 \mathrm{~m}$ height. The mass fractions of air, $\mathrm{SO}_{2}$, and $\mathrm{NO}_{2}$ at the monitoring point and the pollutant diffusion process are recorded during the CFD computation.

\section{CFD Simulations of Air Pollutant Dispersion}

At first, four different wind speeds $(0.5 \mathrm{~m} / \mathrm{s}, 1.0 \mathrm{~m} / \mathrm{s}$, $2.0 \mathrm{~m} / \mathrm{s}$, and $3.0 \mathrm{~m} / \mathrm{s}$ at pedestrian level of $1.5 \mathrm{~m}$ ) are chosen to perform air pollutant dispersion simulations under standard atmospheric conditions at sea level. The global time is set to $200 \mathrm{~s}, 100 \mathrm{~s}, 50 \mathrm{~s}$, and $40 \mathrm{~s}$ for the former wind speeds to guarantee a complete dispersion simulation in the whole computational domain for each scenario. The solution files are saved every second (physical iteration time). For example, Fig. 6 shows the pollutant concentration for the scenario of $U_{z=1.5 \mathrm{~m}}=3.0 \mathrm{~m} / \mathrm{s}$ at $\mathrm{t}=1.0 \mathrm{~s}$ on several $\mathrm{XZ}$ plane slices. It can be seen that the clean air on the left side starts replacing the polluted air on the right side. The pollutant concentration distributions on the five slices are the same because of the statistical assumptions of the RANS method. The middle slice is chosen to show the whole unsteady pollutants dispersion process as shown in Fig. 7. Similar progress can be observed for $\mathrm{NO}_{2}$ dispersion process and for the other scenarios from the initial polluted air to the final clean air. 


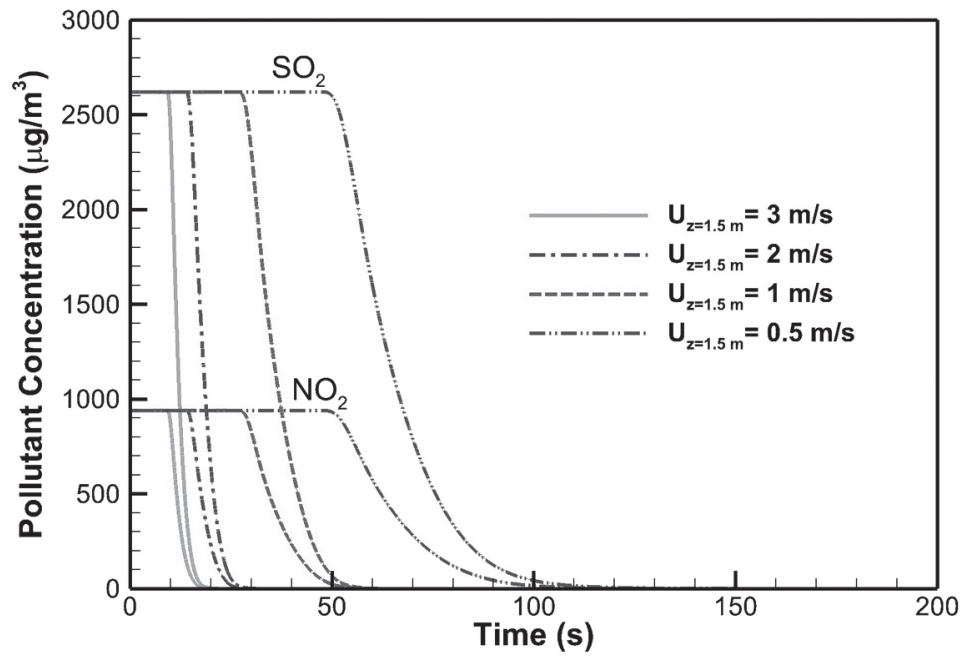

Fig. 8. Time history of the $\mathrm{SO}_{2}$ and $\mathrm{NO}_{2}$ concentration under different wind speeds at the monitoring point $(50 \mathrm{~m}, 1.5 \mathrm{~m})$.

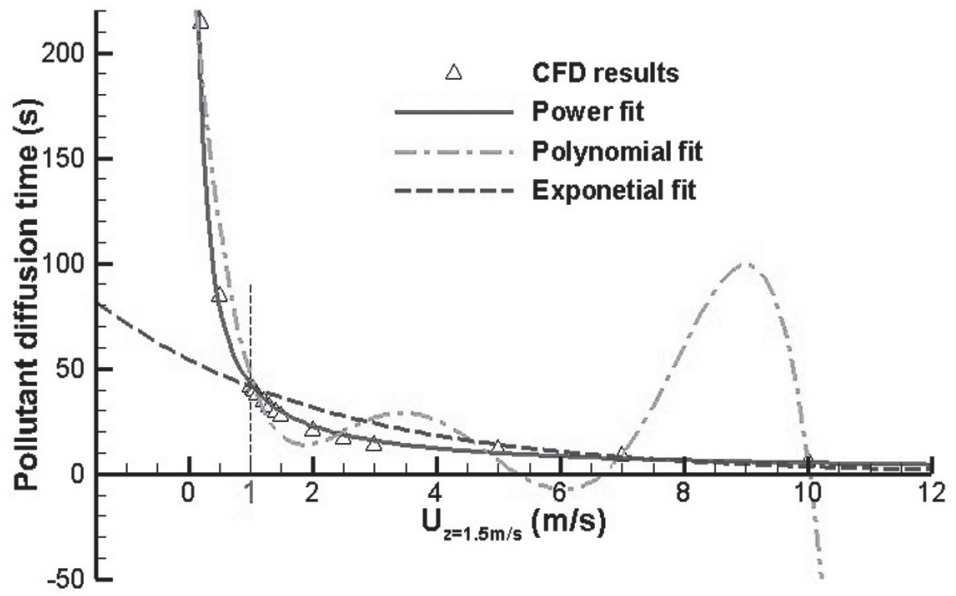

Fig. 9. Time periods of pollutant dispersion at the monitoring point $(50 \mathrm{~m}, 1.5 \mathrm{~m})$ from the end time of $I A Q I=500$ to the beginning time of clean air.

\section{Air Pollutant Dispersion Time}

Focusing on the monitor point $(50 \mathrm{~m}, 1.5 \mathrm{~m})$ on the center of the ground at pedestrian height, Fig. 8 shows the $\mathrm{SO}_{2}$ and $\mathrm{NO}_{2}$ dispersion processes under four different wind speeds. A higher wind speed leads to an earlier and shorter pollutant dispersion (from the end time of $I A Q I=500$ to the beginning time of clean air).
In order to establish the mathematical relationship between wind speed and pollutant diffusion time, at second step, another 12 different wind speeds from $0.2 \mathrm{~m} / \mathrm{s}$ to $10 \mathrm{~m} / \mathrm{s}$ are also chosen to perform the pollutant dispersion simulations. The values of diffusion time under different wind speed are listed in Table 4. These 16 results are fitted though the least square method. The fitting curves obtained by three fitting functions are shown in Fig. 9. The solid line

Table 4. The pollutant dispersion time $T$ under different wind speeds $U_{z=1.5 \mathrm{~m} / \mathrm{s}}$ at the monitoring point $(50 \mathrm{~m}, 1.5 \mathrm{~m})$.

\begin{tabular}{|c|c|c|c|c|c|c|c|}
\hline $\mathrm{U}_{z=1.5}(\mathrm{~m} / \mathrm{s})$ & $\mathrm{T}(\mathrm{s})$ & $\mathrm{U}_{z=1.5}(\mathrm{~m} / \mathrm{s})$ & $\mathrm{T}(\mathrm{s})$ & $\mathrm{U}_{z=1.5}(\mathrm{~m} / \mathrm{s})$ & $\mathrm{T}(\mathrm{s})$ & $\mathrm{U}_{z=1.5}(\mathrm{~m} / \mathrm{s})$ & $\mathrm{T}(\mathrm{s})$ \\
\hline 0.2 & 214.118 & 1.05 & 39.856 & 1.4 & 29.721 & 3.0 & 13.913 \\
\hline 0.5 & 84.455 & 1.1 & 38.022 & 1.5 & 27.805 & 5.0 & 11.705 \\
\hline 1.0 & 41.818 & 1.2 & 34.737 & 2.0 & 20.796 & 7.0 & 8.418 \\
\hline 1.04 & 40.272 & 1.3 & 32.062 & 2.5 & 16.645 & 10.0 & 5.955 \\
\hline
\end{tabular}


is the result of power function fitting, the dash-dotted line is the result of polynomial fitting, and the dashed line is the result of exponential function fitting. The fitting functions of the three curves are:

$$
y=42.4786 x^{-0.8955}
$$

$$
y=260.2-375.1 x+206.2 x^{2}-50.03 x^{3}+5.418 x^{4}-0.2127 x^{5}
$$

$$
y=54.3802 e^{-0.2715 x}
$$

Among the three curves, the power function fitting has the minimum error, and the curve agrees rather well the CFD results, which can reflect the corresponding relationship between pollutant diffusion time and wind speed. According to the characteristics of the corresponding power function curve, in the first quadrant, the function monotonically decreases with two asymptotes (i.e. coordinate axis). When wind speed approaches 0 , the function value approaches infinity. When the speed approaches infinity, the function value approaches 0 . When the speed is in the range from 0 to 1 , the function value changes sharply. When the speed is larger than 1, the function value changes gently. Combined with the physical meaning represented by the curve, it can be seen that when the wind speed is less than $1 \mathrm{~m} / \mathrm{s}$, the diffusion time of pollutants decreases rapidly with the increase of wind speed, and the diffusion efficiency of pollutants is relatively low; when the wind speed is greater than $1 \mathrm{~m} / \mathrm{s}$, the diffusion time of pollutants decreases gently with the increase of wind speed, and the diffusion efficiency of pollutants is relatively high. Therefore, $1 \mathrm{~m} / \mathrm{s}$ can be taken as the critical wind speed that affects the diffusion efficiency of air pollutants.

\section{Discussion}

Although the idealized pollutant dispersion model is very simple, it is believed that the CFD simulation results are able to provide sufficient support for the analysis and outcomes of this study. This model consists of meteorological condition, atmosphere turbulence condition, normal land condition, air pollution condition, multi-species CFD simulation system and other necessary factors. The solution and analysis of simplified model can provide fundamental rules for actual complex urban situations.

For urban wind environment simulation, it is suggested that large-eddy simulation (LES) should be used rather than RANS method due to the existence of large extent separated flow. There are two reasons for the insistence on the use of RANS method in the present study. First, LES can provide accurate instantaneous pulse data, but needs sufficient computing resources. Time costs and computing costs of LES are usually not affordable for most conventional studies. Second, the statistical averaged data is usually more interesting for urban designers. RANS methods have been developed to a very high level of maturity that makes them accurate enough to be used as a scientific research instrument or even an industrial design tool.

\section{Conclusions}

In this study, the direct relation between wind speed and pollutant dispersion is investigated and analyzed. It is affirmed that wind speed is important for air quality improvement. Static wind speed is redefined as the minimum wind speed to improve air quality efficiently. It is a simpler indicator compared with the existing air quality evaluation indicators, and improves the operability of quick and direct evaluation of air quality in urban environments. The whole study can be summarized as follows:

- A CFD method for pollutant dispersion simulation is introduced and validated. The simulation results agree well with the experimental data, indicating that the present CFD method is suitable for contaminant dispersion simulations in complex building environments.

- The static wind speed is redefined for the consideration of the pollutant dispersion efficiency. By investigating the relationship between different wind speeds and the corresponding pollutant diffusion time, it is concluded that the static wind speed should be $1 \mathrm{~m} / \mathrm{s}$ at pedestrian level.

Future research includes but is not limited to: propose a new indicator to evaluate air quality for urban design and planning (a more global perspective) based on the present static wind speed; according the value of this indicator, evaluate the air quality of existing urban area or urban design scheme comprehensively; establish an advanced and efficient optimization system for urban design and planning, with this and other key indicators as optimization objectives, and with optimization algorithm based on artificial intelligence introduced, to guide the urban spatial layout design and reconstruction of existing urban area, to improve urban air quality, to ensure the healthy life of the residents, and finally to achieve the goals of "healthy city" and "green city".

\section{Acknowledgments}

We wish to thank Dr. YU Lei for CFD guidance and language supports.

\section{Conflict of Interest}

The authors declare no conflict of interest. 


\section{References}

1. UN DESA, Prospects for World Urbanization, 2018.

2. WHO, Ambient air pollution: A global assessment of exposure and burden of disease, 2016.

3. FERNANDO H.J.S., LEE S.M., ANDERSON J. PRINCEVAC M., PARDYJAK E. Grossman-Clarke, S. Urban fluid mechanics: air circulation and contaminant dispersion in cities. Environ. Fluid Mech. 1, 107, 2001.

4. GU Z.L., ZHANG Y.W., CHENG Y., LEE S.C. Effect of uneven building layout on air flow and pollutant dispersion in non-uniform street canyons. Build. Environ. 46, 2657, 2011.

5. GROMKE C. A vegetation modeling concept for building and environmental aerodynamics wind tunnel tests and its application in pollutant dispersion studies. Environ. Pollut. 159, 2094, 2011.

6. DU Y.X., BLOCKEN B., PIRKER S. A novel approach to simulate pollutant dispersion in the built environment:Transport-based recurrence CFD. Build. Environ. 170, 1, 2020

7. RIVAS E. SANTIAGO J.L., LECHÓN Y., MARTIN F., ARINO A., Pons J.J., SANTAMARIA J.M. CFD modelling of air quality in Pamplona City (Spain):Assessment, stations spatial representativeness and health impacts valuation. Sci. Total Environ. 649, 1362, 2019.

8. KIKUMOTO H., OOKA R. Large-eddy simulation of pollutant dispersion in a cavity at fine grid resolutions. Build. Environ. 127, 127, 2018.

9. FOROUTAN H., TANG W., HEIST D.K., PERRY S.G., BROUWER L.H., MONBUREAU E.M. Numerical analysis of pollutant dispersion around elongated buildings: An embedded large eddy simulation approach. Atmos. Environ. 187, 117, 2018.

10. CUI P. Y., ZHUO L., TAO W. Q. Numerical investigations on re-independence for the turbulent flow and pollutant dispersion under the urban boundary layer with some experimental validations. Int. J. Heat Mass Tran. 106, 422, 2017.

11. DAVE B., LI A. I. N.. computational fluid dynamics for urban design, J. Wind Engin. \& Industrial Aerody., New Frontiers: Proceedings of the 15th International Conference on Computer-Aided Architectural Design Research, Hong Kong, China. 357, 2010.

12. MCCARTY J., KAZA N. Urban form and air quality in the United States. Landsc. Urban Plan. 139, 168, 2015.

13. YUAN C., SHAN R., ZHANG Y.Y., LI X.X., NORFORD L. Multilayer urban canopy modelling and mapping for traffic pollutant dispersion at high density urban areas. Sci. Total Environ. 647, 255, 2019.

14. LI B., LI X.B., Li C., ZHU Y., PENG Z.R., WANG Z.Y., LU S.J. Impacts of wind fields on the distribution patterns of traffic emitted particles in urban residential areas. Trans. Res. Part D. 68, 122, 2019.

15. GAO Z.L., BRESSON R., QU Y.F., MILLIEZ M., DEMUNCK C., CARISSIMO B. High resolution unsteady RANS simulation of wind, thermal effects and pollution dispersion for studying urban renewal scenarios in a neighborhood of Toulouse. Urban Clim. 23, 114, 2018.

16. BADAS M.G., FERRARI C., GARAU M., QUERZOLI G. On the effect of gable roof on natural ventilation in twodimensional urban canyons. Wind. Eng. Ind. Aerodyn. 162, 24, 2017.

17. ZHANG N., DU Y.S., MIAO S.G. A microscale model for air pollutant dispersion simulation in urban areas: presentation of the model and performance over a single building. Adv. Atmos. Sci. 33, 184, 2016.

18. CUI P.Y., LI Z., TAO W.Q. Buoyancy flows and pollutant dispersion through different scale urban areas: CFD simulations and wind-tunnel measurements. Build. Environ. 104, 76, 2016.

19. YING X. Y., DING G., HU X.J., ZHANG Y.Q. Developing planning indicators for outdoor wind environments of high-rise residential buildings. J. Zhejiang Uni-sci. A. 17, 378, 2016.

20. LAU G.E., NGAN K. Analysing urban ventilation in building arrays with the age spectrum and mean age of pollutants. Build. Environ. 131, 288, 2018.

21. HONG B., LIN B., QIN H.Q. Numerical investigation on the coupled effects of building-tree arrangements on fine particulate matter (PM2.5) dispersion in housing blocks. Sustain. Cities Soc. 34, 358, 2017.

22. AZIZI M. M., JAVANMARDI K. The effects of urban block forms on the patterns of wind and natural ventilation. Procedia Eng. 18, 54, 2017.

23. ANTONIOU N., MONTAZERI H., WIGO H., NEOPHYTOU M.K., BLOCKEN B., SANDBERG M. CFD and wind-tunnel analysis of outdoor ventilation in a real compact heterogeneous urban area: Evaluation using "air delay". Build. Environ. 126, 355, 2017.

24. MIGUEL Á., ALBERTO M., JESÚS F.M. Proposal for a simplified CFD procedure for obtaining patterns of the age of air in outdoor spaces for the natural ventilation of buildings. Energies, 10, 1252, 2017.

25. CHEN L., HANG J. SANDBERG M., CLAESSON L., DI SABATINO S., WIGO H. The impacts of building height variations and building packing densities on flow adjustment and city breathability in idealized urban models. Build. Environ. 118, 344, 2017.

26. HANG J., LUO Z. W. WANG X.M., HE L.J., WANG B.M., ZHU W. The influence of street layouts and viaduct settings on daily carbon monoxide exposure and intake fraction in idealized urban canyons. Environ. Pollut. 220, 72, 2017.

27. YOU W., GAO Z. CHEN Z., DING W.W. Improving residentialwind environments by understanding the relationship between building arrangements and outdoor regional ventilation. Atmosphere, 8, 102, 2017.

28. PARK S. J., WONSIK C., KIM J.J., KIM M.J., PARK R.J., HAN K.S., KANG G. Effects of building roof cooling on the flow and dispersion of reactive pollutants in an idealized urban street canyon. Build. Environ. 109, 175, 2016.

29. CAMMELLI S., WONG B. Urban ventilation design for megacities: Hong Kong and beyond. P. I. Civil. Eng. 169, 35, 2016.

30. KUBILAY A., NEOPHYTOU M.K.A., MATSENTIDES S., LOIZOU M., CARMELIET J. The pollutant removal capacity of urban street canyons as quantified by the pollutant exchange velocity. Urban Clim. 21, 136, 2017.

31. BRITTER R. E., HANNA S. R. Flow and dispersion in urban areas. Annu. Rev. Fluid Mech. 35, 469, 2003.

32. HANG J., LI Y. Age of air and air exchange efficiency in high-rise urban areas and its link to pollutant dilution. Atmos. Environ. 45, 5572, 2011.

33. XIE Z., CASTRO I. P. LES and RANS for turbulent flow over arrays of wall-mounted obstacles. Flow Turbul. Combust. 1, 2006.

34. NEOPHYTOU M. K. A., BRITTER R. E. Modelling of atmospheric dispersion in complex urban topographies: a computational fluid dynamics study of the central London 
area. $5^{\text {th }}$ GRACM Int. Congr. Comput. Mech. Limassol, Cyprus.GR. 967, 2005.

35. LIU C., LEUNG D. Y. C., BARTH M. C. On the prediction of air and pollutant exchange rates in street canyons of different aspect ratios using large-Eddy simulation. Atmos. Environ. 39, 1567, 2005.

36. BUCCOLIERI R., SANDBERG M., SABATINO D. S. City breathability and its link to pollutant concentration distribution within urban-like geometries. Atmos. Environ. 44, 1894, 2010.

37. LIU C. H., LEUNG D.Y.C., BARTH M.C. On the prediction of air and pollutant exchange rates in street canyons of different aspect ratios using large-eddy simulation. Atmos. Environ. 39, 1567, 2005.

38. CHENG W. C., LIU C. H., LEUNG D. Y. C. Computational formulation for the evaluation of street canyon ventilation and pollutant removal performance. Atmos. Environ. 42, 9041, 2008.
39. FRANKE J., HELLSTEN A., SCHLÜNZEN H., CARISSIMO B. Best practice guideline for the CFD simulation of flows in the urban environment. COST Office: Brussels, Belgium, 2007.

40. TOMINAGA Y., MOCHIDA.A., YOSHIE R., KATAOKA H., NOZU T., YOSHIKAWA M., SHIRASAWA T. AIJ guidelines for practical applications of CFD to pedestrian wind environment around buildings. J. Wind. Eng. Ind. Aerodyn. 96, 1749, 2008.

41. HARGREAVES D.M., WRIGHT N.G. On the use of the $k-\varepsilon$ model in commercial CFD software to model the neutral atmospheric boundary layer. J. Wind Eng. \& Industrial Aerodynamics, 95, 355, 2007.

42. DAVIDSON M.J., SNYDER W.H. LAWSON R.E., HUNT J.C.R. Wind tunnel simulations of plume dispersion through groups of obstacles. Atmos. Environ. 30 (22), $3715,1996$. 
